\title{
Integrated Nutrient Management System is Must for Improving Soil Health and Achieving Higher Productivity Goals in the Semi-arid Tropics (SAT)
}

\begin{abstract}
KL Sharma*
Former Principal Scientist and National Fellow (Soil Science), ICAR-Central

Research Institute for Dryland Agriculture, Hyderabad, India

*Corresponding Author: KL Sharma, Former Principal Scientist and National Fellow (Soil Science), ICAR-Central Research Institute for Dryland Agriculture, Hyderabad, India.
\end{abstract}

The semi-arid tropics (SAT) represent about of 48 countries in the developing world. The SAT regions are mostly found in some part of India, locations in south east Asia, some part of subSaharan Africa, much of southern and eastern Africa, and a few locations in Latin America. The climates of the semi-arid tropics (SAT) are characterized by high incidence of solar radiation, high temperatures and very high variable rainfall. Only about $4 \%$ of the arable land of the semi-arid tropics is irrigated. Erratic and inadequate rainfall pattern and frequent dry spells are the predominant features of these regions. Beside severe moisture stress, the soils of the SAT regions are highly impoverished in soil fertility leading to nutrient deficiency in most of the crops. The SAT soils are more suitable for the crops like Sorghum (Sorghum bicolor), castor (Ricinus Communis), pearl millet (Pennisetm typhoides) and other small millets, cow pea (Vigna unguiculata), chickpea (Cicer arietinum L), pigeonpea (Cajanus cajan), groundnut (Arachis hypgaea) and horse gram (Macrotyloma uniflorum). Other crops liked black gram (Vigna mungo) and green gram (Vigna radiata) can also be grown in these soils. It has been understood that apart from biotic stresses caused by plant pathogens, there are numerous abiotic stresses such as extreme temperatures, drought (moisture stress), salinity, nutrient deficiency and radiation which all have deleterious effects on plant growth and ultimately on crop yield.

The rainfed SAT regions have several constraints which limit their productivity. The predominant soil orders which represent rainfed SAT regions in India include Vertosols Alfisols, Vertic -In- ceptisols and other soils. Some of the constraints in Vertisols include susceptibility to erosion, poor workability of soil during the kharif season, low hydraulic conductivity, poor drainage, hard setting tendencies, high calcium carbonate content, low organic matter content, low available nitrogen, low available phosphorus, sulfur and zinc. Research experience also reveal that without the application of moderate doses of phosphate, nitrogen and occasional application of zinc sulfate, the satisfactory yields of crops are not possible.

In Alfisol soils, the predominant constraints include shallow soil depth, low water storage capacity, hard setting tendencies and crust formation due to predominance of hydrous oxides iron (Fe) and aluminium (Al). These soils are also low in organic matter and available soil nutrients like nitrogen, phosphorus, zinc, sulphur etc. Consequently, these soil exhibit high responses to the added fertilisers. There are instances that even potassium which was not a limiting factor for crop production in these soils few decades back, have started becoming limiting due to the continuous cropping. The nutrient deficiency and responsiveness to fertilizer application on the farmers' fields is much greater than on the research farms.

\section{Food production targets and nutrient needs}

No doubt, the country showed good progress in the food grain production which was about 52 million tonnes in 1951-52, increased to 284.95 million tonnes in 2018- 19. While the target for 2019-20 was kept at 291.10 million tonnes in view of the domes-

Citation: KL Sharma. "Integrated Nutrient Management System is Must for Improving Soil Health and Achieving Higher Productivity Goals in the Semi-arid Tropics (SAT)". Acta Scientific Agriculture 5.11 (2021): 12-14. 
tic requirement of food grains and to ensure adequate surplus for export. The semiarid tropics contribute significantly to the food basket of the country despite several abiotic stresses. Among these stresses, inherently low soil fertility leading to nutrient stress is a matter of serious concern. Several reports on fertility of soils in India highlight that bedside macronutrient like $\mathrm{N}, \mathrm{P}$ and $\mathrm{K}$, many micronutrients and secondary nutrient like $\mathrm{S}$ are also deficient in Indian soils especially in the SAT. Beside this, degradation of fertility of SAT soils due to soil erosion, depletion of organic matter owing to higher soil temperature leading to its fast decomposition, loss of soil nutrients through nitrate leaching, ammonia volatilisation, denitrification, higher nutrient removal-use gap, imbalanced fertilisation etc further aggravate the nutrient deficiency in these soils. Though based on the reports of soil testing program launched in the recent few years by Govt. of India, initiatives have been taken to advise the farming community to use balanced fertilisation, but still much dent has not been made to ensure the balanced fertilisation. This could be attributed to several reasons such as lack of initiative on the part of the farmers, non-availability of fertilisers at the crucial period of crop growth, low purchasing power etc. Moreover, the demand of inorganic fertiliser is more than their domestic production in the country. According to the impact study of 'Soil Health Card Scheme' (SHCS) conducted by the National Institute of Agricultural Extension Management, India consumed about 25.6 million tonnes of fertilizers, mostly nitrogen (17 million tonnes) followed by phosphorous ( 6 million tonnes) and potassium (2.5 million tonnes) during 2018. In 2018, the fertilizer consumption of India was 175 kilograms per hectare. Fertilizer consumption of India increased from 12.4 kilograms per hectare in 1969 to 175 kilograms per hectare in 2018, growing at an average annual rate of $5.96 \%$. According to some other estimates, the domestic production of fertiliser nutrients $\left(\mathrm{N}+\mathrm{P}_{2} \mathrm{O}_{5}\right)$ during 201920 was to the extent of 18.51 million tonnes and the import during the same period was about 9.93 million tonnes which included $\mathrm{K}_{2} \mathrm{O}$ also, the total availability was 28.97 million tonnes. The consumption of the above three fertiliser nutrient during the same year was about 27.23 million tonnes. Consequently, there was a neck to neck competition between the availability and consumption of fertiliser nutrients in the country. Similarly, there was a considerable gap reported between the nutrient addition to the crops and nutrient removal by the crops, which is expected to widen in the years to come to meet the higher food targets, and may aggravate the soil fertility related productivity constraints in the future. Beside widening of the removal use gap, there is an imbalance in the use of fertilizer nutrient also. It has been assessed that the imbalanced consumption ratio of $6.2: 4: 1$ (N: P: K) during 1990-91 further widened to 7:2.7:1 in 2000-01 and 5:2:1 in 2009-10. However, the desirable nutrient use ratio is considered as $4: 2: 1$. The fertilizer consumption in India is grossly imbalanced since beginning. It is more biased towards $\mathrm{N}$ followed by $\mathrm{P}$. The decontrol of phosphatic and potassic fertilizers resulted in more than doubling the prices of phosphatic and potassic fertilizers and consequently highly disturbed the nutrient use ratios. As food grain production increased with time, the number of elements becoming deficient increased. Therefore, the use of alternative sources of nutrients in combination with inorganic fertilisers i.e. integrated nutrient management or conjunctive nutrient management is inevitable in the semi-arid tropics and need to be given more emphasis. The intergraded use of locally available organic sources of nutrients with the farmer and inorganic chemical fertilisers can be very effective solution for (i) reducing the requirement of chemical fertilisers, (ii) improving the use efficiency of applied inorganic fertilisers, (iii) to increase the soil organic matter and improve the soil physical, chemical and biological properties (iv) to rede the environmental pollution (air and water) and reduction in the green house gas emission (GHG's) and consequent mitigation of global warming.

Integrated nutrient management (INM) concept, components and scope

The basic concept underlying the integrated nutrient management system (INMS), nevertheless, remains the maintenance and possible improvement of soil fertility for sustained crop productivity on long term-basis and also to reduce the cost on inorganic (fertilizer) input. During 1998, the Food and Agriculture Organisation has expressed that the three main components of INMS could be i). maintain or enhance soil productivity through a balanced use of fertilizers combined with organic and biological sources of plant nutrients, ii) improve the stock of plant nutrients in the soils, and iii) improve the efficiency of plant nutrients, thus, limiting losses to the environment. Thus, the integrated nutrient management/ supply (INM) aims at maintenance or adjustment of soil fertility and of plant nutrient supply to an optimum level for sustaining the desired crop productivity through optimization of benefit from all possible sources of plant nutrients available with the farmer or in the market at the cheaper rate in an integrated manner. As 
mentioned above, the basic objectives of integrated plant nutrient supply (IPNS) are to reduce the inorganic fertilizer requirement, to restore organic matter in soil, to enhance nutrient use efficiency (NUE) and to maintain soil quality in terms of physical, chemical and biological properties.

Thus, integrated nutrient management is a holistic approach to optimizing the plant nutrient supply. It includes: (i) assessing residual soil nutrient supplies, as well as acidity and salinity; (ii) determining soil productivity potential for various crops through assessment of various soil physical, chemical and biological properties (iii) calculating crop nutrient requirements for the specific site and yield objective; (iv) quantifying nutrient value of on-farm resources such as manures and crop residues; (v) calculating supplemental nutrient needs (total nutrient requirement minus on-farm available nutrients) that must be met with "off-farm" nutrient sources; (vi) developing a programme to optimize nutrient utilization through selection of appropriate nutrient sources, application timings and placement. The overall objective of INM is to adequately feed the crop as efficiently as possible, while minimizing the potentially ill effects to the environment.

The important components of integrated nutrient management for rainfed semiarid tropics could be (i) Diagnostic balanced fertilization, (ii) Capitalization of Legume effect, (iii) Inter cropping with legumes, (iv) Crop rotation with legumes, (v) Crop sequence with legumes, (vi) crop residue management and its effective recycling, (vii) Green leaf manuring, (viii-situ green manuring, (viii) Organic manuring (use of composts, FYM and vermicompost, poultry manure), (ix) Use of symbiotic and a symbiotic biofertilizer strains, (x) Nitrogen fixing tree based nutrient cycling in agro-forestry systems, (xi) Optimization of response to INM practices by adopting in-situ soil-water conservation practices/Land treatments-following watershed approach.

Several long term studies conducted in rainfed agriculture have indicated that it is possible to substitute a good part of fertilizer $\mathrm{N}$ needs of kharif crops by farmyard manure (FYM) without any adverse effect on the total productivity of the system in major cropping systems such as rice-rice, rice-wheat, maize-wheat, sorghumwheat, pearl millet-wheat, maize-wheat and rice-maize. Organic manures alone cannot supply sufficient $P$ for optimum crop growth because of their inadequate availability and low $\mathrm{P}$ concentration. Although, bulky organic manures may not be able to supply ad- equate amount of nutrients, nevertheless their role becomes important in improving the various soil quality parameters (physical, chemical and biological). At present, the use of chemical fertilizers is high in rice, wheat, sugarcane and cotton. Wherever available, organic manures are invariably used in some vegetable crops like potato, onion, chillies, spices like ginger and turmeric, in cereals like rice, in commercial crops like sugarcane, cotton and fruit crops. Green manuring is very prominent in rice and sugarcane. The use of organic manures is high in arid and semi-arid zones where rainfall/irrigation water or soil moisture is a limitation. Farmers are also aware of the need for organics in dry land agriculture where some sort of stability to production is ensured because of their possible role in soil structure improvement and moisture storage and its supply. But the application of organic manures to soil is declining progressively with the time, may be due to alternate uses of cattle dung as domestic fuel and reducing population of cattle especially, bollocks etc. because of more focus on use of machinery for draft purpose.

To conclude, it is emphasized that there is an urgent need to develop strong policies to explore the use of alternative sources of nutrient as listed above. The farmers should be encouraged and motivated in this direction, and if required, suitable micro-infrastructure should be developed at grassroot level to develop and process these resources using the 'state of the art' technology. Integrated nutrient management approach will not only help in balanced nutrition of the crops, to reduce the dependence on chemical fertilizers and environment safety but will also be very effective in improving soil health and overall functional capacity of (Soil Quality) and soil quality indices, which is very important for SAT regions to break the low yield barriers.

"The Nation that Destroys its Soil, Destroys itself" - Franklin D. Roosevelt.

\section{Volume 5 Issue 11 November 2021 (C) All rights are reserved by KL Sharma.}

